\title{
OPEN Exposure to acute normobaric hypoxia results in adaptions of both the macro- and microcirculatory system
}

Moritz Mirna $\mathbb{1}^{1,9}$, Nana-Yaw Bimpong-Buta ${ }^{2,9}$, Fabian Hoffmann ${ }^{3,4}$, Thaer Abusamrah ${ }^{2}$, Thorben Knost ${ }^{2}$, Oliver Sander ${ }^{5}$, Yayu Monica Hew ${ }^{6}$, Michael Lichtenauer ${ }^{1}$, Johanna M. Muessig ${ }^{2}$, Raphael Romano Bruno², Malte Kelm², Jochen Zange ${ }^{3}$, Jilada Wilhelm ${ }^{3}$, Ulrich Limper ${ }^{3,7}$, Jens Jordan ${ }^{3,8}$, Jens Tank ${ }^{3}$ \& Christian Jung ${ }^{2}$

Although acute hypoxia is of utmost pathophysiologic relevance in health and disease, studies on its effects on both the macro- and microcirculation are scarce. Herein, we provide a comprehensive analysis of the effects of acute normobaric hypoxia on human macro- and microcirculation. 20 healthy participants were enrolled in this study. Hypoxia was induced in a normobaric hypoxia chamber by decreasing the partial pressure of oxygen in inhaled air stepwisely $\left(\mathrm{pO}_{2} ; 21.25 \mathrm{kPa}(0 \mathrm{k}), 16.42 \mathrm{kPa}\right.$ $(2 \mathrm{k}), 12.63 \mathrm{kPa}(4 \mathrm{k})$ and $9.64 \mathrm{kPa}(6 \mathrm{k}))$. Macrocirculatory effects were assessed by cardiac output measurements, microcirculatory changes were investigated by sidestream dark-field imaging in the sublingual capillary bed and videocapillaroscopy at the nailfold. Exposure to hypoxia resulted in a decrease of systemic vascular resistance $(p<0.0001)$ and diastolic blood pressure $(p=0.014)$. Concomitantly, we observed an increase in heart rate $(p<0.0001)$ and an increase of cardiac output $(p<0.0001)$. In the sublingual microcirculation, exposure to hypoxia resulted in an increase of total vessel density, proportion of perfused vessels and perfused vessel density. Furthermore, we observed an increase in peripheral capillary density. Exposure to acute hypoxia results in vasodilatation of resistance arteries, as well as recruitment of microvessels of the central and peripheral microcirculation. The observed macro- and microcirculatory effects are most likely a result from compensatory mechanisms to ensure adequate tissue oxygenation.

\author{
Abbreviations \\ AMS Acute mountain sickness \\ $\mathrm{CaO}_{2}$ Arterial oxygen content \\ CD Peripheral capillary diameter \\ CO Cardiac output \\ CPI Cardiac performance index \\ DBP Diastolic blood pressure \\ $\mathrm{DO}_{2} \quad$ Oxygen delivery \\ $\mathrm{FiO}_{2}$ Fraction of inspired oxygen \\ $\mathrm{kPa} \quad$ Kilopascal \\ HR Heart rate
}

\footnotetext{
${ }^{1}$ Division of Cardiology, Department of Internal Medicine II, Paracelsus Medical University of Salzburg, Muellner Hauptstrasse 48, 5020 Salzburg, Austria. ${ }^{2}$ Department of Cardiology, Pulmonology and Vascular Medicine, Medical Faculty, Heinrich-Heine-University, Duesseldorf, Germany. ${ }^{3}$ German Aerospace Center (DLR), Institute of Aerospace Medicine, Cologne, Germany. ${ }^{4}$ Department of Cardiology, University Hospital Cologne, Cologne, Germany. ${ }^{5}$ Department of Rheumatology, Hiller Research Institute for Rheumatology, Medical Faculty, Heinrich-Heine-University, Duesseldorf, Germany. ${ }^{6}$ Department of Aeronautics and Astronautics, Stanford University, Stanford, CA 94305, USA. ${ }^{7}$ Department of Anesthesiology and Intensive Care Medicine, Merheim Medical Center, Hospitals of Cologne, University of Witten/Herdecke, Cologne, Germany. ${ }^{8}$ Chair of Aerospace Medicine, Medical Faculty, University of Cologne, Cologne, Germany. ${ }^{9}$ These authors contributed equally: Moritz Mirna and Nana-Yaw Bimpong-Buta. ${ }^{\square}$ email: christian.jung@med.uni-duesseldorf.de
} 
LLS Lake Louise Score

NC Number of crossings

NIRS Near-infrared spectroscopy

PCD Peripheral capillary recruitment

$\mathrm{pCO}_{2} \quad$ Partial pressure of carbon dioxide

PNC Perfused number of crossings

$\mathrm{pO}_{2} \quad$ Partial pressure of oxygen

PPV Proportion of perfused vessels

PVD Perfused vessel density

SBP Systolic blood pressure

SV Stroke volume

SVR Systemic vascular resistance

$\mathrm{THb}$ Total hemoglobin concentration

TSI Tissue saturation index

TVD Total vessel density

The microcirculatory system comprises a network of small blood vessels with a pivotal role in maintaining adequate tissue perfusion, oxygenation and nutrient supply at the cellular level. Anatomically, the network consists of arterioles, venules and capillaries, with diameters well below $100 \mu \mathrm{m}^{1}$. Current evidence suggests that the microcirculation plays a paramount role in the pathophysiology of multi-organ failure in critically ill patients, which is why the evaluation of microcirculatory disorders is gaining increasing recognition in intensive care medicine ${ }^{2}$. In fact, reduced cardiac output, changes in peripheral vascular resistance or alterations of the volume status or $\mathrm{pH}$-value can lead to microcirculatory disorders, which result in tissue edema ${ }^{3,4}$, inadequate tissue perfusion and, subsequently, reduced cellular oxygen supply ${ }^{2,5}$. The resulting tissue hypoxia markedly aggravates tissue damage and thus promotes end-organ dysfunction in critically ill patients with sepsis or shock ${ }^{6}$, which is why the restoration of tissue perfusion and oxygenation constitutes a paramount treatment goal in clinical practice ${ }^{5}$.

Tissue hypoxia resulting from an inadequate uptake of ambient oxygen or an increase in cellular oxygen demand is one of the key features of the critically ill patient ${ }^{7}$. Since hypoxaemia, defined as a decrease in arterial oxygen tension $^{8}$, is also a predominant feature of the high-altitude environment, research on the pathophysiologic processes behind hypoxia was significantly facilitated with the advent of altitude simulation tests ${ }^{9}$. On the cellular level, hypoxic stress initiates a transcriptional response by hypoxia inducible factors (HIF; during intermittent hypoxia predominately HIF-1 $a^{10-12}$ ), which leads to a reduction of cellular energy consumption, a secretion of pro-angiogenic and survival factors ${ }^{10}$, and qualitative changes in mitochondrial function ${ }^{13}$, which in turn results in alterations of the cardiovascular, haematological and even urinary physiology ${ }^{14,15}$. Among the observed physiological alterations in response to hypoxia, the effects on the human macrocirculatory system have been subject to several extensive scientific investigations in the past. Hence, acute hypoxia is known to result in an initial increase in heart rate, blood pressure and cardiac output, whereas a decrease in stroke volume can be observed only after a few days of exposure ${ }^{16-18}$. In contrast, studies concerning the effects of hypoxia on the microcirculatory system are comparatively scarce. For example, previous studies reported an increase in sublingual microcirculatory blood flow and capillary density after ascent to high altitudes ${ }^{19,20}$, which suggests microvascular recruitment after exposure to hypobaric hypoxia ${ }^{21}$. However, recent studies also reported that the physiological adaptions to hypobaric hypoxia can differ substantially from those to normobaric hypoxia ${ }^{22,23}$, which is why the results of studies conducted in high altitude can not be fully applied to the normobaric environment.

Since the microcirculation constitutes one of the central components where hypoxia mediates its unfavourable effects in critically ill patients, a thorough investigation of the effects of normobaric hypoxia on the microcirculatory system, with regards to its interplay with larger vessels, is of interest. To further elucidate this matter, we conducted an altitude simulation test and investigated both the macro- and microcirculatory effects of acute normobaric hypoxia (Fig. 1 provides an overview of the conducted measurements).

\section{Results}

In total, we enrolled 20 healthy subjects in this study, who had no significant experience in climbing or competitive sports. Of the subjects enrolled, the majority was male $(n=11,55 \%)$, the median age was 29 years (IQR 25-31) and the median body mass index (BMI) was $23 \mathrm{~kg} / \mathrm{m}^{2}$ (IQR 21-25.3). At baseline, the median systolic blood pressure (SBP) was $115 \mathrm{mmHg}$ (IQR 106-128), the median diastolic blood pressure (DBP) was $70 \mathrm{mmHg}$ (IQR 64.5-75), the median heart rate (HR) was 67 beats per minute (bpm; IQR 61.5-70), the median peripheral oxygen staturation $\left(\mathrm{SpO}_{2}\right)$ was $97 \%$ (IQR 96-98) and the median respiratory rate was $16 \mathrm{~min}^{-1}$ (IQR $14-17$, see Table 1). Eighteen subjects completed the entire hypoxia protocol.

The atmospheric data of the two hypoxia runs are displayed in Supplementary Figure 1. Briefly, the partial pressure of oxygen $\left(\mathrm{pO}_{2}\right)$ in ambient air decreased significantly throughout the two hypoxia runs, whereas humidity, temperature, overall pressure and the partial pressure of carbon dioxide $\left(\mathrm{pCO}_{2}\right)$ remained relatively stable.

Regarding symptoms of acute mountain sickness (AMS), the median Lake Louise Score (LLS) at baseline was 0.2 points (IQR $0.0-0.6$ ), with a gradual increase to the median LLS of 3.8 points (IQR $1.7-4.4$ ) at $6 \mathrm{k}$.

Exposure to hypoxia resulted in a significant decrease of DBP, but it did not result in a change of SBP. Whereas HR increased significantly throughout the two tests, stroke volume remained unchanged. Systemic vascular resistance decreased, whereas cardiac output $(\mathrm{CO})$ and cardiac performance index (CPI) increased significantly (see Fig. 2, Table 2 and Suppl. Figure 2). Furthermore, exposure to hypoxia resulted in a significant decrease of $\mathrm{SpO}_{2}$ and a signficant increase in respiratory rate, as expected (see Table 2). Notably, there was no 


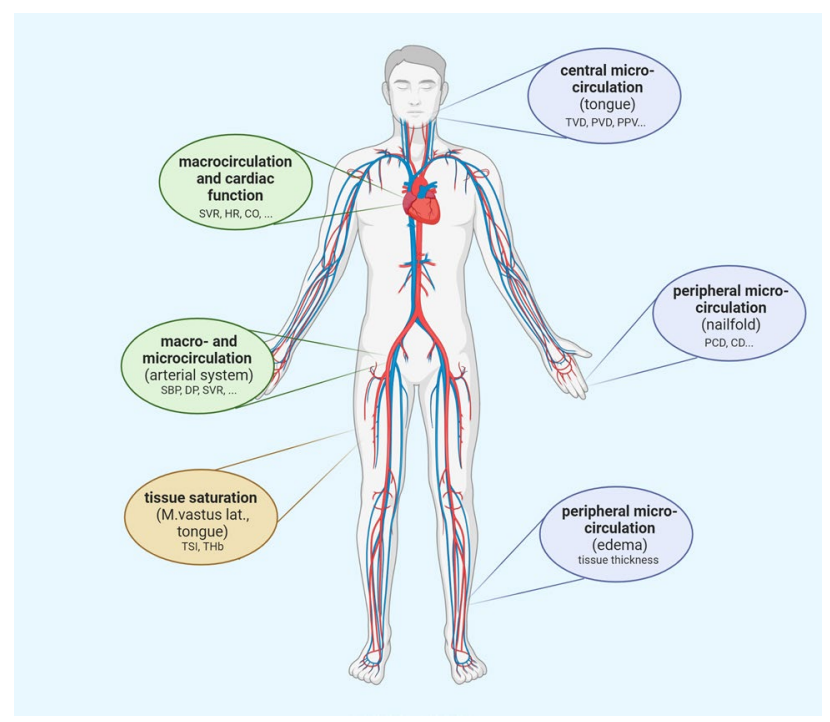

Figure 1. Schematic representation of the conducted measurements during the two hypoxia tests. TVD total vessel density, $P P V$ proportion of perfused vessels, $P V D$ perfused vessel density, $P C D$ peripheral capillary recruitment, $C D$ peripheral capillary diameter, $S V$ stroke volume, $H R$ heart rate, $C O$ cardiac output, $S B P$ systolic blood pressure, $D B P$ diastolic blood pressure, $S V R$ systemic vascular resistance, $T S I$ tissue saturation index, $T H b$ total hemoglobin concentration.

\begin{tabular}{|l|l|l|}
\hline & $\%$ & n (total = 20) \\
\hline Sex $(\%$ male) & 55 & 11 \\
\hline Age (years) & Median & IQR \\
\hline BMI $\left(\mathrm{kg} / \mathrm{m}^{2}\right)$ & 29 & $25-31$ \\
\hline Height $(\mathrm{cm})$ & 23 & $21-25.3$ \\
\hline Weight $(\mathrm{kg})$ & 176.5 & $169.5-181.3$ \\
\hline Systolic blood pressure $(\mathrm{mmHg})$ & 115 & $106-128$ \\
\hline Diastolic blood pressure $(\mathrm{mmHg})$ & 70 & $64.5-75$ \\
\hline Heart rate $($ bpm) & 67 & $61.5-70$ \\
\hline Respiratory rate $\left(\right.$ min $\left.^{-1}\right)$ & 16 & $14-17$ \\
\hline Peripheral oxygen saturation $(\%)$ & 97 & $96-98$ \\
\hline
\end{tabular}

Table 1. Baseline characteristics of the subjects enrolled.

change in oxygen delivery $\left(\mathrm{DO}_{2}\right)$, although a trend towards an initial decrease, followed by an increase to $6 \mathrm{k}$, was observed (see Table 2).

In the sublingual microcirculation, acute hypoxia resulted in an increase in the number of crossings (NC), total vessel density (TVD), perfused number of crossings (PNC), proportion of perfused vessels (PPV) and perfused vessel density (PVD; see Fig. 3, Table 2 and Suppl. Figure 2).

In the capillary bed of the nailfold, we observed a significant increase in peripheral capillary recruitment $(\mathrm{PCD})$ at $2 \mathrm{k}$ and $4 \mathrm{k}$ when compared to the baseline values ( $0 \mathrm{k}$ mean: $78.33 \%$ vs. $2 \mathrm{k:} 84.72 \%$ and $4 \mathrm{k:} 83.01 \%$, $p<0.01$, see Fig. 3, Table 2 and Supplementary Figure 3). Correspondingly, the mean peripheral capillary diameter (CD) of arterial limb $(11.6 \mu \mathrm{m}$ at $0 \mathrm{k})$, apex $(16.6 \mu \mathrm{m}$ at $0 \mathrm{k})$ and venous $\operatorname{limb}(15.7 \mu \mathrm{m}$ at $0 \mathrm{k})$ showed a significant increase of $4 \%$ at $2 \mathrm{k}$ (all $p<0.05$ ) and $2 \%$ at $4 \mathrm{k}$ (apex significant at $p=0.049$ ). As estimated by the law of Hagen-Poiseuille ${ }^{24}$, which states that the flow rate is proportional to the radius of the vessel to the fourth power, the average flow increases corresponded to $17 \%(2 \mathrm{k})$ and $8 \%(4 \mathrm{k})$ and additionally $5 \%$ due to the increased capillary recruitment. Notably, the initial increase in PCD and CD was followed by a decrease in both variables at $6 \mathrm{k}$ (see Table 2). A graphical overview of the findings concerning the macro- and microcirulatory system is provided in Supplementary Figure 2.

Changes in peripheral microcirculation did not result in clinical signs of increased microvascular permeability, since we observed no significant peripheral edema after hypoxia, as assessed by ultrasonographic tissue thickness of the lower leg or the forehead (see Table 2).

Concerning tissue oxygenation, we found only moderately diverging baseline values of the tissue saturation index (TSI) in both muscles at rest (see Table 2), but total hemoglobin concentration (THb) was almost three 

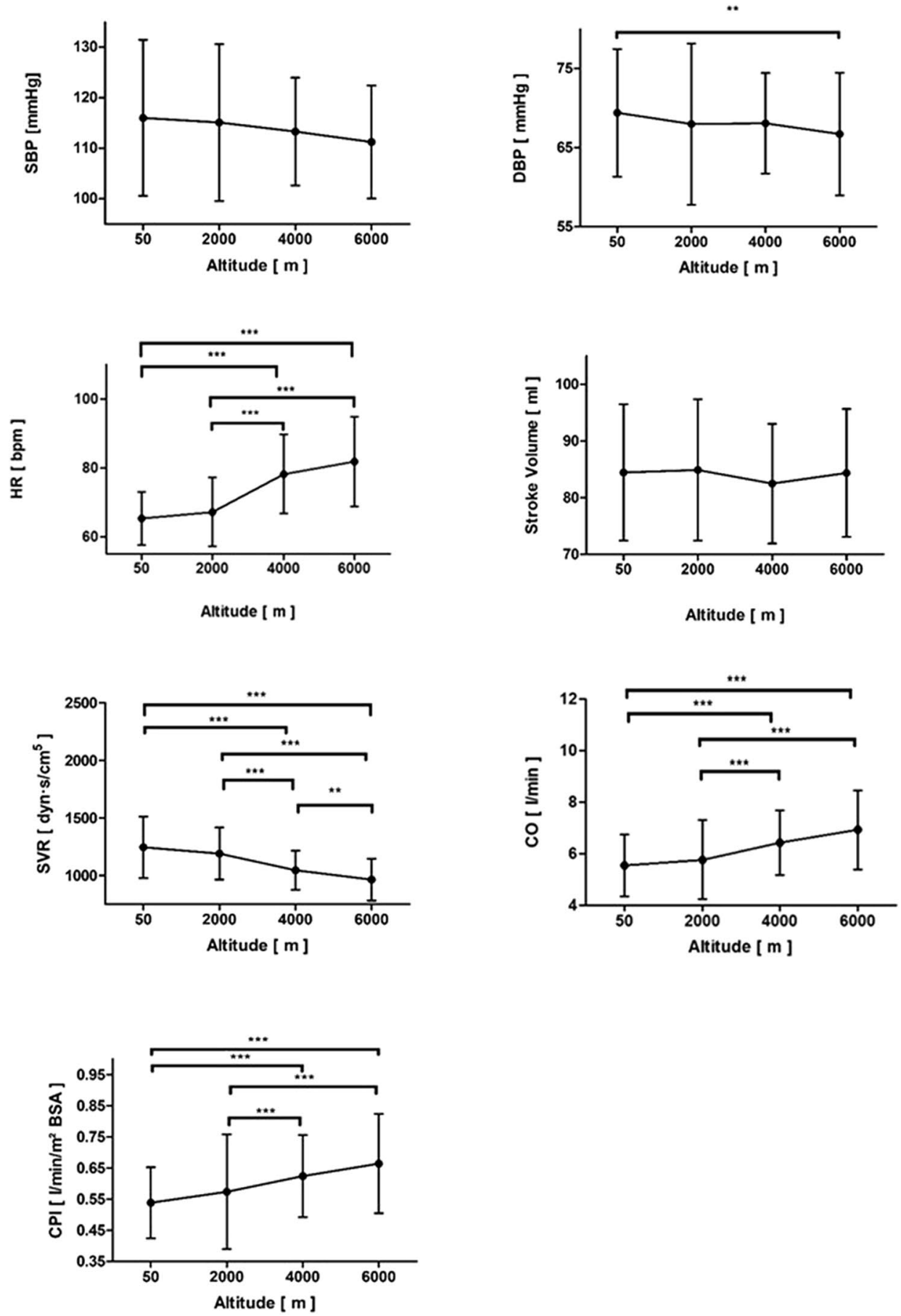

Figure 2. Systolic blood pressure (SBP), diastolic blood pressure (DBP), heart rate (HR), stroke volume (SV), systemic vascular resistance (SVR), cardiac output (CO) and cardiac performance index (CPI) throughout the altitude simulation test. ${ }^{\star} p<0.05,{ }^{* *} p<0.01$ and ${ }^{* * *} p<0.001$.

times higher in the tongue than in the vastus lateralis muscle. Similar to the decrease in $\mathrm{SpO}_{2}$, hypoxia resulted in a statistically significant, yet comparatively low change of the TSI of the tongue at $4 \mathrm{k}$ and $6 \mathrm{k}$ (baseline: mean $63.6 \%$ to $4 \mathrm{k}$ : mean $58.3 \%, p=0.01$, and $6 \mathrm{k}$ : mean $59.7 \%, p=0.009$ ) and of the vastus lateralis muscle at $6 \mathrm{k}$ (baseline: mean $69.6 \%$ to $6 \mathrm{k}$ : mean $66.4 \%, p=0.013)$ when compared to the respective baseline values. In the tongue, however, the decrease in TSI in reponse to hypoxia reached statistical significance at more moderate levels of hypoxia and was in total more pronounced than in the vastus lateralis muscle. The THb was not significantly influenced by exposure to hypoxia (see Fig. 4 and Table 2). Also, the systemic red blood cell counts (RBC) and hemoglobin concentration remained unchangend (see Table 2). 


\begin{tabular}{|c|c|c|c|c|c|c|c|c|c|}
\hline & \multicolumn{2}{|c|}{$50 \mathrm{~m}(0 \mathrm{k})$} & \multicolumn{2}{|c|}{$2000 \mathrm{~m}(2 \mathrm{k})$} & \multicolumn{2}{|c|}{$4000 \mathrm{~m}(4 \mathrm{k})$} & \multicolumn{2}{|c|}{$6000 \mathrm{~m}(6 \mathrm{k})$} & \multirow[b]{2}{*}{$p$ value } \\
\hline & Median & IQR & Median & IQR & Median & IQR & Median & IQR & \\
\hline \multicolumn{10}{|c|}{ Hemorheological variables } \\
\hline $\begin{array}{l}\text { Red blood cell count } \\
\text { (per pL) }\end{array}$ & 4.9 & $4.3-5.5$ & 4.9 & $4.2-5.4$ & 4.9 & $4.3-5.4$ & 4.9 & $4.3-5.3$ & 0.984 \\
\hline Hemoglobin $(\mathrm{g} / \mathrm{dl})$ & 14.8 & $12.9-15.7$ & 14.4 & $13.0-15.7$ & 14.5 & $12.8-15.5$ & 14.6 & $12.7-15.5$ & 0.944 \\
\hline $\begin{array}{l}\text { Arterial oxygen content } \\
(\mathrm{ml} / \mathrm{dl})\end{array}$ & 20.7 & $18.2-22.2$ & 19.2 & $17.1-21.7$ & 17.3 & $15.3-19.0$ & 15.7 & $13.6-17.4$ & $<0.0001$ \\
\hline $\begin{array}{l}\text { Oxygen delivery (ml/ } \\
\text { min) }\end{array}$ & 1105 & $971.8-1189$ & 1069 & $950.4-1209$ & 1040 & 916.4-1139 & 1128 & $977.2-1255$ & 0.455 \\
\hline \multicolumn{10}{|l|}{ Macrocirculation } \\
\hline $\begin{array}{l}\text { Peripheral oxygen } \\
\text { saturation (\%) }\end{array}$ & 97 & $97-97.5$ & 95 & $93-97$ & 84 & $80-87$ & 80 & $67-83.5$ & $<0.0001$ \\
\hline $\begin{array}{l}\text { Respiratory rate } \\
\text { (breaths per minute) }\end{array}$ & 16 & $14-16$ & 18 & $16-18$ & 18 & $16-22$ & 24 & $21-28$ & $<0.0001$ \\
\hline $\begin{array}{l}\text { Systolic blood pressure } \\
(\mathrm{mmHg})\end{array}$ & 115 & $105-130$ & 114 & $103-122$ & 116 & $103-119$ & 110 & $104-122$ & 0.251 \\
\hline $\begin{array}{l}\text { Diastolic blood pressure } \\
\text { (mmHg) }\end{array}$ & 70 & $63-76$ & 68 & $58-75$ & 66 & $64-70$ & 65 & $63-74$ & 0.014 \\
\hline $\begin{array}{l}\text { Systemic vascular resist- } \\
\text { ance }\left(\text { dynes }^{\star} \mathrm{s} / \mathrm{cm}^{5}\right)\end{array}$ & 1206 & $1072-1421$ & 1199 & $982-1352$ & 1067 & $951-1152$ & 940 & $814-1125$ & $<0.0001$ \\
\hline Heart rate $(\mathrm{bpm})$ & 65 & $60-70$ & 66 & $61-72$ & 76 & 69-86 & 80 & 73-92 & $<0.0001$ \\
\hline Stroke volume $(\mathrm{ml})$ & 83 & $77-91$ & 84 & $78-93$ & 82 & $76-89$ & 87 & $78-93$ & 0.281 \\
\hline Cardiac output (1/min) & 5.35 & $4.60-6.08$ & 5.56 & $4.80-6.40$ & 6.00 & $5.60-7.00$ & 7.20 & $5.60-8.10$ & $<0.0001$ \\
\hline $\begin{array}{l}\text { Cardiac performance } \\
\text { index }\left(1 / \mathrm{min} / \mathrm{m}^{2} \mathrm{BSA}\right)\end{array}$ & 0.51 & $0.48-0.59$ & 0.53 & $0.48-0.63$ & 0.60 & $0.54-0.69$ & 0.67 & $0.53-0.75$ & $<0.0001$ \\
\hline \multicolumn{10}{|c|}{ Sublingual microcirulation } \\
\hline $\begin{array}{l}\text { Perfused number of } \\
\text { crossings }\end{array}$ & 32 & $27-37$ & 33 & $27-40$ & 35 & 29-39 & 36 & $30-42$ & $<0.0001$ \\
\hline $\begin{array}{l}\text { Perfused vessel density } \\
\left(\mathrm{mm} / \mathrm{mm}^{2}\right)\end{array}$ & 6.8 & $5.7-7.8$ & 7.0 & $5.7-8.5$ & 7.4 & $6.2-8.3$ & 7.7 & $6.4-8.9$ & $<0.0001$ \\
\hline $\begin{array}{l}\text { Proportion of perfused } \\
\text { vessels (\%) }\end{array}$ & 94 & $89-97$ & 94 & $89-98$ & 95 & $90-98$ & 95 & $91-100$ & 0.017 \\
\hline Number of crossings & 34 & $30-39$ & 36 & $30-42$ & 37 & $31-42$ & 39 & $32-44$ & $<0.0001$ \\
\hline \multirow[t]{2}{*}{$\begin{array}{l}\text { Total vessel density } \\
\left(\mathrm{mm} / \mathrm{mm}^{2}\right)\end{array}$} & 7.2 & $6.4-8.3$ & 7.7 & $6.4-8.9$ & 7.9 & $6.6-8.9$ & 8.3 & $6.9-9.4$ & $<0.0001$ \\
\hline & Mean & SEM & Mean & SEM & Mean & SEM & Mean & SEM & $p$ value \\
\hline \multicolumn{10}{|c|}{ Peripheral microcirculation } \\
\hline Vessel density $\left(\mathrm{n} / \mathrm{mm}^{2}\right)$ & 6.69 & 1.51 & 7.26 & 1.72 & 7.07 & 1.94 & 7.29 & 1.74 & $<0.01$ \\
\hline $\begin{array}{l}\text { Peripheral capillary } \\
\text { recruitment (\%) }\end{array}$ & 78.33 & 0.15 & 84.72 & 0.15 & 83.01 & 0.17 & 83.45 & 0.14 & $<0.01$ \\
\hline \multirow[t]{3}{*}{$\begin{array}{l}\text { Peripheral capillary } \\
\text { diameter, apex }(\mu \mathrm{m})\end{array}$} & 16.58 & 7.77 & 17.32 & 8.09 & 16.99 & 8.26 & 17.14 & 8.12 & 0.01 \\
\hline & \multicolumn{2}{|l|}{ Baseline } & & & & & \multicolumn{2}{|c|}{ Post hypoxia } & \\
\hline & Median & IQR & & & & & Median & IQR & $p$ value \\
\hline \multicolumn{10}{|c|}{ Peripheral edema (tissue thickness) } \\
\hline $\operatorname{Leg}(\mathrm{mm})$ & 5.14 & $4.4-7.0$ & & & & & 5.54 & $4.7-6.4$ & 0.936 \\
\hline \multirow[t]{2}{*}{ Forehead $(\mathrm{mm})$} & 4.85 & $4.4-5.8$ & & & & & 4.98 & $4.4-5.6$ & 0.184 \\
\hline & Mean & SEM & Mean & SEM & Mean & SEM & Mean & SEM & $p$ value \\
\hline \multicolumn{10}{|c|}{ Tissue oxygen saturation } \\
\hline $\begin{array}{l}\text { Tissue saturation index } \\
\text { tongue (\%) }\end{array}$ & 63.57 & 1.27 & 61.51 & 0.90 & 58.31 & 1.10 & 59.66 & 0.98 & 0.044 \\
\hline $\begin{array}{l}\text { Tissue saturation index } \\
\text { M.vastus lat. (\%) }\end{array}$ & 69.59 & 0.81 & 69.58 & 0.62 & 68.23 & 0.97 & 66.37 & 1.10 & 0.145 \\
\hline $\begin{array}{l}\text { Total hemoglobin } \\
\text { tongue }(\mu \mathrm{mol} / \mathrm{l})\end{array}$ & 129.5 & 4.14 & 136.3 & 5.56 & 123.1 & 6.91 & 123.8 & 7.24 & 0.356 \\
\hline $\begin{array}{l}\text { Total hemoglobin } \\
\text { M.vastus lat. }(\mu \mathrm{mol} / \mathrm{l})\end{array}$ & 48.27 & 3.94 & 46.83 & 3.56 & 49.57 & 4.48 & 48.43 & 4.20 & 0.997 \\
\hline
\end{tabular}

Table 2. Investigated variables throughout the altitude simulation tests.

In the two hypoxia runs conducted, a total of 2 subjects had to exit the test prematurely because of severe symptoms of AMS. These two participants did not show any difference in the investigated macro- and microcirculatory variables when compared to participants who did not exit the tests prematurely. 

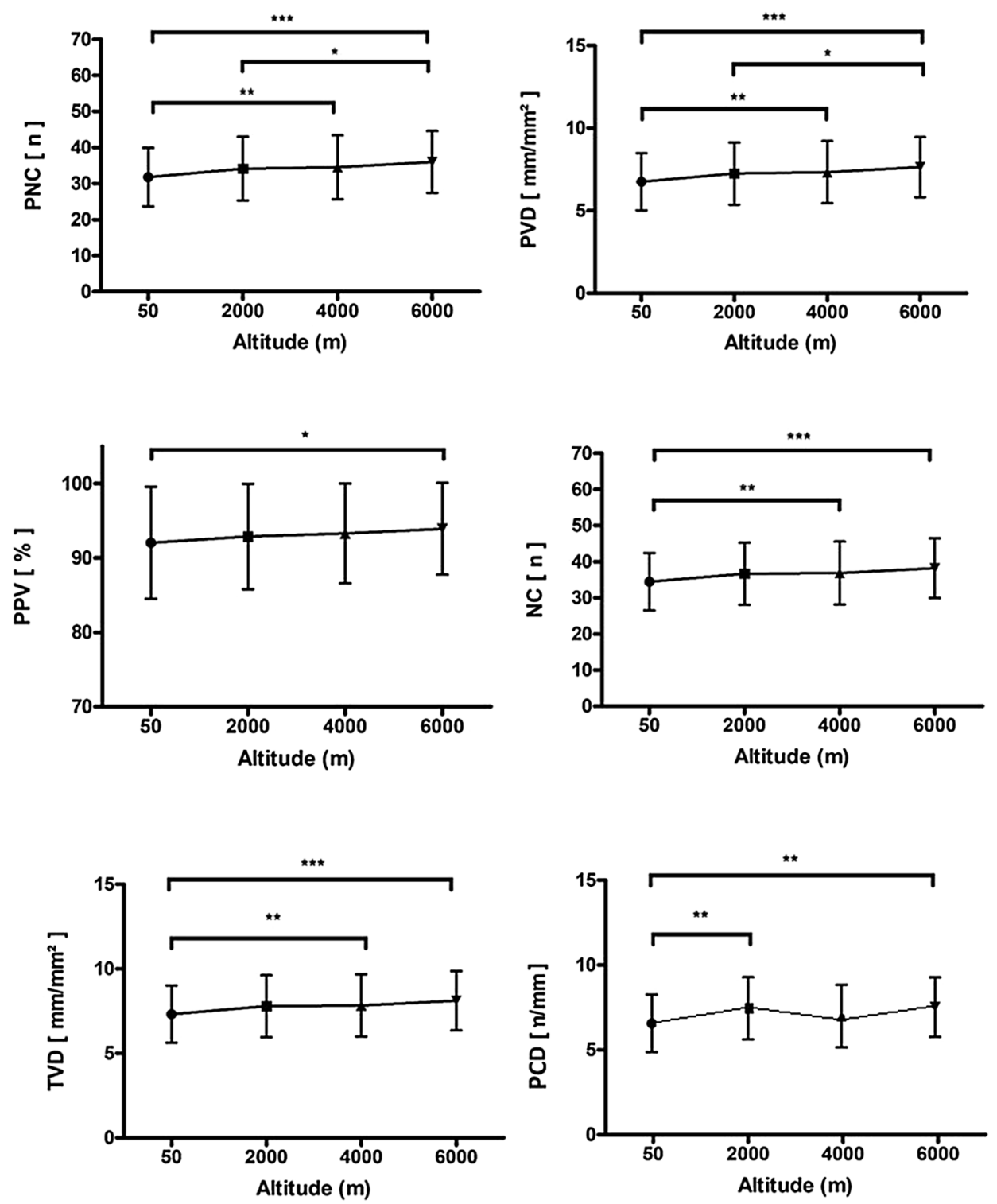

Figure 3. Perfused number of crossings (PNC), perfused vessel density (PVD), proportion of perfused vessels (PPV), number of crossings (NC), total vessel density (TVD), and peripheral capillary recruitment (PCD) throughout the altitude simulation test. ${ }^{*} p<0.05,{ }^{* *} p<0.01$ and ${ }^{* *} p<0.001$.

Participants who showed objective hypoxia, as portrayed by an $\mathrm{SpO}_{2}<75 \%$ at $6 \mathrm{k}\left(\mathrm{SpO}_{2}<75 \%: \mathrm{n}=8\right)$ had a significantly higher LLS at $2 \mathrm{k}$ (median 1.7 vs. $0.5, p=0.015$ ), but a significantly lower respiratory rate at $6 \mathrm{k}$ (median 21.3 breathspm vs. 27.7 breathspm $p=0.026$ ). Moreover, the increase in HR from baseline to $6 \mathrm{k}$ was significantly higher in these patients (Delta HR at $6 \mathrm{k}: 23.8$ vs. 10.1, $p=0.036$ ).

Supplementary Table 1 depicts an overview of the differences between female and male participants, while the rest of the investigated variables were not different between the two genders. Compared to male participants, we observed a significantly lower SBP, DBP and THb of the vastus lateralis muscle in female subjects.

\section{Discussion}

In the last decades, several studies have investigated the effects of hypoxia on the human macrocirculation. According to current evidence, chronic hypoxia leads to a significant increase of systolic and diastolic blood pressure by an overstimulation of the adrenergic and renin-angiotensin system ${ }^{25,26}$, as well as a downregulation of endothelial NO synthase (eNOS) ${ }^{27}$. Hence, long-term hypoxia is regarded a key precursor in the pathogenesis of arterial hypertension in patients with obstructive sleep apnea (OSA ${ }^{28}$. In contrast, acute hypoxia is known to result in local or systemic vasodilatation via nitric oxide (NO), which is a direct result of enhanced secretion of adenosine, adenosine triphosphate (ATP), prostaglandins (PGs) and adrenaline ${ }^{29}$, and constitutes a compensatory mechanism to ensure adequate tissue perfusion ${ }^{30,31}$. 


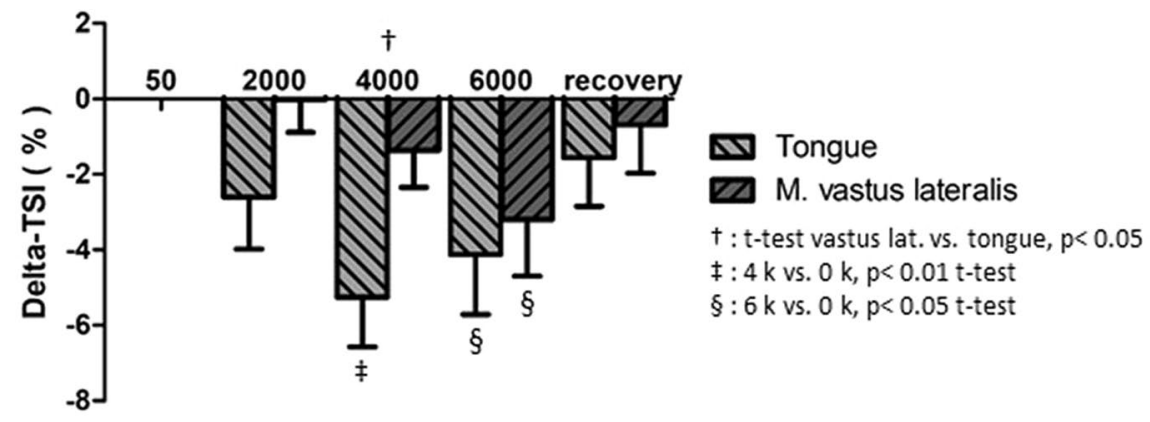

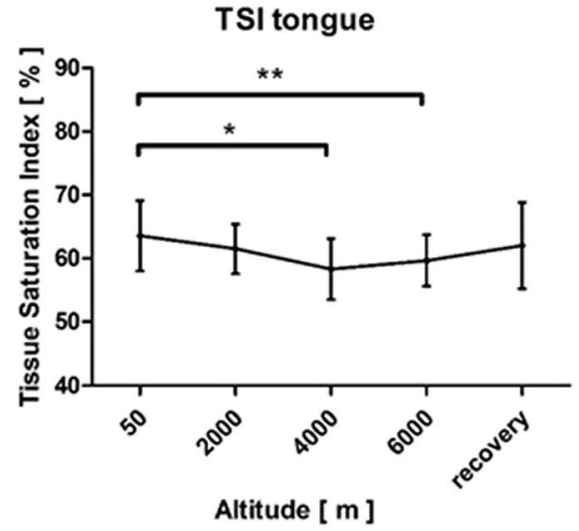

$\mathrm{THb}$ tongue

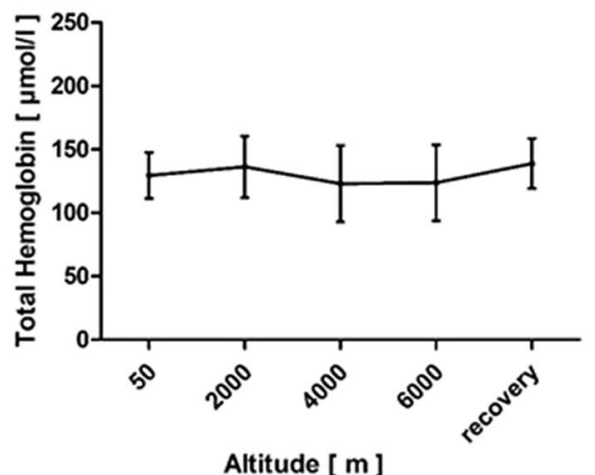

TSI M.vastus lat.

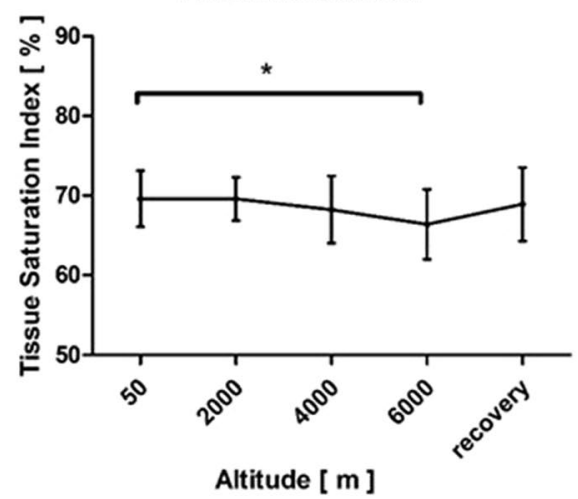

THb M.vastus lat.

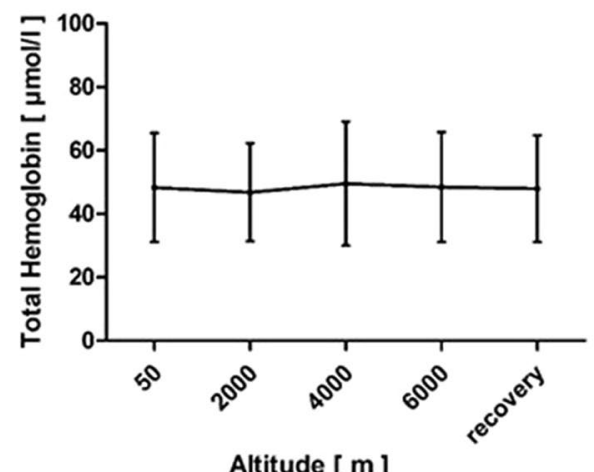

Altitude [ $\mathrm{m}$ ]

Figure 4. Tissue saturation index (TSI), Delta-TSI and total hemoglobin concentration (THb) of the tongue and the vastus lateralis muscle throughout the hypoxia test. $\dagger$ denotes the t-test of vastus lat. versus tongue at $4 \mathrm{k}$, where the $p$ value was $<0.05$; $\ddagger$ denotes the t-tests of the tongue and vastus lat. at $4 \mathrm{k}$ versus $0 \mathrm{k}$, where the $p$ value was $<0.01 ; \S$ denotes the t-test of the tongue at $6 \mathrm{k}$ versus $0 \mathrm{k}$, where the $p$ value was $<0.05 .{ }^{\star} p<0.05,{ }^{* *} p<0.01$ and ${ }^{* * *} p<0.001$.

In our study, exposure to normobaric hypoxia resulted in profound systemic hypoxaemia, as portrayed by a significant decrease in $\mathrm{SpO}_{2}$. In contrast, decreases in TSI of the tongue and of the vastus lateralis muscle were comparatively low and probably clinically irrelevant. However, the response of TSI to hypoxia was more sensitive and pronounced in the tongue than in the leg muscle (Delta-TSI tongue min. $-5.3 \%$ at $4 \mathrm{k}$, Delta-TSI vastus lateralis muscle min. $-3.2 \%$ at $6 \mathrm{k}$, see Fig. 4 ), which indicates that hypoxia was predominantly compensated by an increased perfusion in both muscles at rest, with a more effective compensation in the vastus lateralis muscle, which is also adapted to high increases in energy turn-over during work.

Similar to previous studies ${ }^{30,31}$, we found that exposure to acute hypoxia resulted in a decrease of DBP. This finding was most likely a result from vasodilatation of the arterioles, as portrayed by a significant decrease in SVR. Concomitantly, we observed a compensatory increase in HR which, since there was no significant change in stroke volume, resulted in an increased $\mathrm{CO}(\mathrm{CO}=\mathrm{HR} \times \mathrm{SV})$ and $\mathrm{CPI}$.

The observed macrocirculatory effects of systemic hypoxaemia were accompanied by microcircultatory changes, which indicate an increase in organ perfusion. Hence, we found that exposure to normobaric hypoxia leads to a significant increase in TVD, PPV and PVD of the sublingual microcirculation, which can be interpreted 
as a result of capillary recruitment. Capillary recruitment is known as an opening of previously closed capillaries by dilatation of the precapillary sphincters in response to unmet metabolic demands ${ }^{32}$. In fact, only $20-30 \%$ of the capillaries are actively participating in tissue perfusion under resting conditions $s^{33}$. Therefore, capillary recruitment constitutes an important compensatory mechanism to ensure adequate tissue perfusion and oxygenation in the capillary beds of several muscles ${ }^{34}$ and the lungs ${ }^{35}$. Notably, our findings are in line with the results of a previous study by Hilty et al. ${ }^{21}$, who found that exposure to high altitudes was associated with capillary recruitment of sublingual capillaries and thus an increase in microcirculatory oxygen extraction capacity.

Similar to the microcirulation of the sublingual capillary bed, we observed a significant increase in PCD and $\mathrm{CD}$ in the microcirculation of the nailfold. This indicates capillary recruitment in the peripheral microcirculation by exposure to acute hypoxia. Notably, Paparde et al. recently reported that acute hypoxia does not influence capillary recruitment in human nailfold capillaries, but rather leads to capillary vasodilatation ${ }^{36}$. Since capillary recruitment is a rapid adaptation, the short duration of hypoxia in this study is no plausible explanation for the discrepancy of the study's results to our current findings. In our study cohort, however, we were able to identify identical areas of the nailfold where we could demonstrate capillary recruitment directly (e.g. capillaries visible at $2 \mathrm{k}$ that were not visible at $0 \mathrm{k}$, see Supplementary Figure 3) and could calculate recruitment rates fitting to the expected increase in circulation. Furthermore, in contrast to hypoxia, hyperoxia was recently found to reduce capillary recruitment ${ }^{37}$. Considering our current data and this previous finding, it seems plausible and credible that dysregulations of the $\mathrm{pO}_{2}$ in blood affect the microcirculation of the nailfold.

In the last decades, clinicians have increasingly recognized the role of the microcirculatory system in the pathophysiology of different diseases. In fact, current evidence suggests, that microcirculatory disorders are a key component of the processes involved in the pathogenesis of multi-organ failure in critically ill patients ${ }^{2}$. Hence, microcirculatory dysfunctions can be found in a large proportion of patients admitted to intensive care units. For example, a reduction in PPV and PVD can be observed in patients with sepsis, and can be interpreted as a result of the impairment of the functional perfusion of the microcirculation ${ }^{6,38,39}$. Microcirculatory disorders themselves can result in tissue hypoxia, which markedly aggravates end-organ dysfunction in critically ill patients ${ }^{6}$. In fact, microcirculatory changes could even be associated with adverse outcomes in several previous studies $^{40}$, which is why the restoration of adequate tissue perfusion and oxygenation constitutes a paramount treatment goal in clinical practice.

The observed macro- and microcirculatory effects of acute hypoxia in healthy participants in our study are most likely a result from compensatory mechanisms which ensure adequate tissue perfusion in case of profound hypoxaemia. Hence, by recruiting microvessels of the central and peripheral microcirculation, the organism adapts to hypoxaemia to counteract the state of inadequate tissue oxygenation. In fact, tissue hypoxia resulting from inadequate uptake of ambient oxygen or an increase in cellular oxygen demand is one of the key features of the critically ill patient ${ }^{7}$. However, whether the observed compensatory mechanisms also occur in the hypoxaemic patient, and, if absent or reduced microcirculatory adaptions are associated with adverse outcomes, remains to be elucidated in clinical trials.

\section{Materials and methods}

The study protocol of this exploratory study was reviewed and approved by the ethics committee of the HeinrichHeine-University, Düsseldorf, Germany (5925R) and conducted according to the principles of the Declaration of Helsinki and Good Clinical Practice. Informed consent was obtained from all subjects before enrollment.

The study was conducted at the 'DLR:envihab' of the German Aerospace Center (https://www.dlr.de/envih $\mathrm{ab} /$ ), Cologne, Germany. In total, 20 healthy subjects without significant experience in climbing or competitive sports were enrolled by an announcement at the University of Düsseldorf. The anthropometric data and baseline characteristics of the study participants are depicted in Table 1.

Induction of hypoxia, measurement of oxygen delivery and Lake Louise Score (LLS). Baseline measurements of 20 healthy participants were acquired under normoxic conditions and compared to measurements under normobaric hypoxic conditions. Hypoxia tests were performed in a normobaric hypoxia chamber, which comprises a laboratory space of about $120 \mathrm{~m}^{2}$ including examination rooms, sanitary facilities and a big common room where subjects could move freely and where they waited for individual examinations. Hypoxia was achieved by nitrogen dilution through the air conditioning system in the atmoshperic self-sufficient hypoxia chamber. Nitrogen was supplied by an external tank. Hence, four different altitudes above sea level were simu-

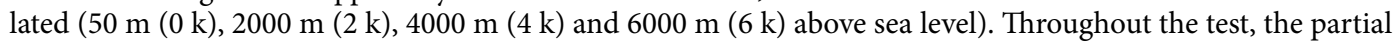
pressure of nitrogen in ambient air was gradually increased, which led to a reduction of the partial pressure of oxygen $\left(\mathrm{pO}_{2} ; 21.25 \mathrm{kPa}(0 \mathrm{k}), 16.42 \mathrm{kPa}(2 \mathrm{k}), 12.63 \mathrm{kPa}(4 \mathrm{k})\right.$ and $9.64 \mathrm{kPa}(6 \mathrm{k}), \mathrm{FiO} 2$ : median $0.21(0 \mathrm{k})$, $0.16(2 \mathrm{k}), 0.12(4 \mathrm{k}), 0.10(6 \mathrm{k})$, see Supplementary Figure 1). The partial pressure of carbon dioxide remained relatively stable throughout the two hypoxia runs $\left(\mathrm{pCO}_{2}\right.$ median $0.046 \mathrm{kPa}(0 \mathrm{k}), 0.060 \mathrm{kPa}(2 \mathrm{k}), 0.72 \mathrm{kPa}(4 \mathrm{k})$ and $0.059 \mathrm{kPa}(6 \mathrm{k}))$. The subjects were exposed to an 'altitude' for two hours before proceeding to the next level. Measurements were performed at each oxygen level to investigate the effects of hypoxia on the micro- and macrocirculation (Fig. 1 provides an overview).

Oxygen delivery $\left(\mathrm{DO}_{2}\right)$ was calculated as previously published $\left(\mathrm{DO}_{2}=\right.$ cardiac output $(\mathrm{CO}) \times \mathrm{CaO}_{2} \times 10$; where $\mathrm{CaO}_{2}$ was the arterial $\mathrm{O}_{2}$-content defined as: $\left(1.34 \times\right.$ hemoglobin concentration $\left.\times \mathrm{SpO}_{2}\right)+\left(0.003 \times \mathrm{PaO}_{2}\right)$ and the amount of dissolved oxygen in blood was estimated by $\left.0.003 \times \mathrm{pO}_{2}\right)^{41}$. Hemoglobin concentration and red blood cell count (RBC) were measured at each of the four different altitudes using an ABL800 FLEX blood gas analyzer (Radiometer Medical, Copenhagen, Denmark). 
Symptoms of hypoxia and severity of acute mountain sickness (AMS) were assessed by the Lake Louise Score (LLS), as previously published. Mild AMS was defined as LLS 3-5 points, moderate AMS as 6-9 points, and severe AMS as $10-12$ points $^{42}$.

Macrocirculation and cardiac function. Systolic and diastolic blood pressure (SBP and DBP) were assessed using a ProBP 3400 (Welch Allyn, Skaneateles Falls, New York, USA) blood pressure monitor, peripheral oxygen saturation was assessed using a PULOX PO-300 (Novidion, Cologne, Germany) pulse oximeter. Systemic vascular resistance (SVR), heart rate (HR), cardiac output (CO), cardiac performance index (CPI) and stroke volume (SV) were measured using transthoracic impedance cardiography (ICON, OSYPKA Medical, Berlin, Germany) and non-invasive Electrical Cardiometry (EC, OSYPKA Medical, Berlin, Germany).

Central and peripheral microcirculation. A sidestream darkfield microscope (MicroScan device, MicroVision Medical, Amsterdam, The Netherlands) was used to assess the sublingual microcirculation as described previously ${ }^{43}$. Only sufficiently trained researchers performed measurements. In brief, on the tip of this device, a highly sensitive camera digitally recorded the sublingual capillary network. Different regions under the tongue were used for all videos and at least four videos were taken per area. In the next step, a tablet computer was used (Microsoft Surface Pro 4, (Redmond, Washington, USA)) for video analysis. After recording videos with sufficient quality, a validated automatic algorithm-software (AVA, Version 4.3 C, MicroVision Medical, Amsterdam, The Netherlands) was used to perform the offline analysis. Agreeing to the second consensus on the assessment of sublingual microcirculation in critically ill patients (European Society of Intensive Care Medicine), the following variables were assessed ${ }^{44}$ :

Microvascular values can offer information about both convexity and diffusion. The proportion of perfused vessels (PPV $=100 *$ (Total number of perfused vessels / total number of vessels) gives information both about convexity and perfusion. Diffusion can be assessed by the total vessel density (TVD) and the number of crossings (NC). Density was evaluated by the total vessel density and the number of crossings. With both information, the perfused vessel density ( $\mathrm{PVD}=$ total length of perfused vessels divided by the analyzed area) and perfused number of crossings ( $\mathrm{PNC}=$ number of vessel crossings with continuous flow) can be calculated. Vessels with diameters of less than $20 \mathrm{~mm}$ correspond mostly to capillaries and are primarily responsible for the microcirculation. These small vessel values are signed with the prefix "s" (e.g. sPPV = PPV of small vessels). The values for all vessels can be considered as a quality check to exclude for example pressure artifacts. Before AVA 4.3C analysis, all videos were evaluated according to the microcirculation image quality score (MIQS), that were originally introduced by Massey et al. ${ }^{45}$. In brief, MIQS rates the acquired videos into three categories: "good", "acceptable", and "non-acceptable". Overall, six different criteria are evaluated: illumination, focus, content, stability, pressure, and the duration was not rated. A video without significant impairment in all criteria gets zero points. Mild impairment results in 1 point for each impaired criterion. Severe impairment in one criterion is defined to be rated with 10 points, which results in the category "non-acceptable".

Peripheral microcirculation at the nailfold was assessed at two areas of fingers III-V of both hands, images of the nailfold of $1 \mathrm{~mm}$ were obtained using videocapillaroscopy (Di-Li 2100, Distelkamp-Electronic, Kaiserslautern, Germany). The acquired images were assigned to each other and identical capillaries were compared in density (PCD), visibility (visible 1 , scanty 0.5 , not visible 0 , not shown $\mathrm{x}$ ), shape (hairpin 1 , tortuous 2 , abnormal 3 ), distance (to the right capillary $50 \mu \mathrm{m}$ before apex in $\mu \mathrm{m}$ ), diameter (CD) of the arterial limb (50 $\mu \mathrm{m}$ before apex in $\mu \mathrm{m})$, apical (in the middle in $\mu \mathrm{m})$, venous limb $(50 \mu \mathrm{m}$ behind apex in $\mu \mathrm{m})$ and tail (diameter between arterial and venous limb $50 \mu \mathrm{m}$ from apex in $\mu \mathrm{m}$ ).

Assessment of the microcirculation was conducted according to the current recommendations of the European Society of Intensive Care Medicine ${ }^{44}$.

Peripheral microcirculation and edema. To investigate whether microcirculatory disorders resulting from generalized hypoxia cause peripheral edema, we performed ultrasonographic measurements of the tissue thickness of the leg and the forehead in supine position. Measurements were conducted in the evening before the hypoxia tests and immediately after the subject left the hypoxic atmosphere. Tissue thickness was measured repeatedly by ultrasound (10-18 MHz linear-probe) at both the anterior tibia and the midline forehead locations (MyLab25, Esaote, Genova, Italy). In more detail, a self-made mechanical fixture device was used to avoid measurement bias due to hand-held measurements and different surface pressure of the ultrasound probe on tissue. In addition an automatic, Matlab (Matlab 2017b, The MathWorks Inc., Natick, USA) based tissue identification software was used to reliably estimate tissue thickness. The software enables automatic and robust tissue thickness estimation from the ultrasound images to minimize analysis biases and improves analysis efficiency during tissue thickness identification and evaluation. The average tissue thickness was calculated from the central section of the ultrasound image (only $50 \%$ of the image at the center) to reduce calculation bias caused by the imaging technique. Tissue thickness was defined as the distance between the surfaces of the skin and the tibia and frontal bone, respectively.

Tissue oxygenation. We investigated the effects of hypoxia on oxygen saturation and blood content of the muscles by assessing the tissue saturation index $\left(\mathrm{TSI}=100^{*}\left(\mathrm{O}_{2} \mathrm{Hb}\right) /\left(\mathrm{O}_{2} \mathrm{Hb}+(\mathrm{HHb}) ; \mathrm{O}_{2} \mathrm{Hb}=\right.\right.$ oxygenated hemoglobin, $\mathrm{HHb}=$ desoxygenated hemoglobin) and the content of total hemoglobin $\left(\mathrm{THb}=\mathrm{O}_{2} \mathrm{Hb}+\mathrm{HHb}\right)$ in the vastus lateralis muscle and the tongue by near-infrared spectroscopy (NIRS) at each of the different altitude levels and after the end of the hypoxia tests. For the examination of vastus lateralis muscle we placed a PortaMon device (Artinis Medical Systems, Elst, The Netherlands) over the belly of the muscle. For measuring the tongue 
we used the PortaLite device (Artinis Medical Systems, Elst, The Netherlands) placing the sensor part on the tongue after shielding it from saliva fluid using a thin plastic foil.

Statistical analysis. Statistical analysis was conducted using GraphPad Prism software (GraphPad Software, USA) and SPSS (Version 24.0, SPSSS Inc., USA). Normally distributed data were expressed as mean and standard error of the mean (SEM), whereas not normally distributed data were shown as median and interquartile range (IQR). A Kolmogorov-Smirnov test was used to test the distribution of data for normality. Medians of the data on micro- and macrocirculation were analyzed using a Kruskal-Wallis test with Dunn's post-hoc test, data on the tissue thickness were analyzed using a Wilcoxon signed-rank test, and data on the TSI and THb of the muscles were interpreted by applying a Student's t-test and a Linear Mixed Effects (LME)-analysis. A $p$ value $<0.05$ was considered statistically significant.

Ethics approval. The study was reviewed and approved by the ethics committee of the Heinrich-HeineUniversity, Düsseldorf, Germany (5925R) and conducted according to the principles of the Declaration of Helsinki and Good Clinical Practice. Informed consent was obtained from all subjects before enrollment.

\section{Conclusions}

Exposure to acute normobaric hypoxia results in enhanced perfusion of the central and peripheral microcirculation, as well as an increase in cardiac output. The observed macro- and microcirculatory effects are most likely a result from compensatory mechanisms to ensure adequate tissue perfusion in case of profound hypoxaemia.

\section{Limitations}

Since this study was an exploratory study, we did not conduct a statistical power calculation prior to enrollment. Hence, a type one error can not certainly be excluded. Another limitation is that SVR, CO, CPI and SV were investigated using transthoracic impedance cardiography, which is less accurate than invasive methods. Due to the technique of impedance cardiography, which is based on calculations derived from the basic laws of electricity, several limitations and possibilities for bias arise ${ }^{46,47}$, which have to be taken into consideration when interpreting the findings of our study. However, invasive methods, such as thermodilution, are labor- and timeintensive and unsuitable for the narrow setting of a hypoxia chamber. Hence, we chose transthoracic impedance cardiography over invasive methods in our study.

\section{Perspectives}

Herein, we provide a comprehensive analysis of the effects of acute normobaric hypoxia on the macro- and microcirculation in healthy subjects. Our findings can contribute to the understanding of health and disease, since hypoxia and the following systemic reactions are of utmost relevance in the pathophysiology of various diseases.

\section{Data availability}

The datasets generated during and analyzed during the current study are available from the corresponding author on reasonable request.

Received: 23 June 2020; Accepted: 14 October 2020

Published online: 01 December 2020

\section{References}

1. Thiele, H. et al. Intraaortic balloon support for myocardial infarction with cardiogenic shock. N. Engl. J. Med. 367, 1287-1296 (2012).

2. Jung, C. \& Kelm, M. Evaluation of the microcirculation in critically ill patients. Clin. Hemorheol. Microcirc. 61, 213-224 (2015).

3. Fuchs, C., Ertmer, C. \& Rehberg, S. Effects of vasodilators on haemodynamic coherence. Best Pract. Res. Clin. Anaesthesiol. 30, 479-489 (2016).

4. Senra Barros, B., Kakkos, S. K., De Maeseneer, M. \& Nicolaides, A. N. Chronic venous disease: from symptoms to microcirculation. Int. Angiol. 38, 211-218 (2019).

5. Jung, C., Jung, F. \& Kelm, M. The microcirculation in hypoxia: the center of the battlefield for oxygen. Clin. Hemorheol. Microcirc. 63, 169-172 (2016).

6. De Backer, D., Creteur, J., Preiser, J.-C., Dubois, M.-J. \& Vincent, J.-L. Microvascular blood flow is altered in patients with sepsis. Am. J. Respir. Crit. Care Med. 166, 98-104 (2002).

7. Damiani, E., Donati, A. \& Girardis, M. Oxygen in the critically ill. Curr. Opin. Anaesthesiol. 31, 129-135 (2018).

8. Samuel, J. \& Franklin, C. Hypoxemia and Hypoxia. In Common Surgical Diseases 391-394 (Springer New York, 2008). https://doi. org/10.1007/978-0-387-75246-4_97.

9. Grocott, M., Montgomery, H. \& Vercueil, A. High-altitude physiology and pathophysiology: implications and relevance for intensive care medicine. Crit. Care 11, 203 (2007).

10. Majmundar, A. J., Wong, W. J. \& Simon, M. C. Hypoxia-inducible factors and the response to hypoxic stress. Mol. Cell 40, 294-309 (2010).

11. Lee, J. W., Bae, S. H., Jeong, J. W., Kim, S. H. \& Kim, K. W. Hypoxia-inducible factor (HIF-1)a: its protein stability and biological functions. Exp. Mol. Med. 36, 1-12 (2004).

12. Dengler, V. L., Galbraith, M. D. \& Espinosa, J. M. Transcriptional regulation by hypoxia inducible factors. Crit. Rev. Biochem. Mol. Biol. 49, 1-15 (2014).

13. Balestra, G. M., Legrand, M. \& Ince, C. Microcirculation and mitochondria in sepsis: getting out of breath. Curr. Opin. Anaesthesiol. 22, 184-190 (2009).

14. Verratti, V. et al. Urinary physiology and hypoxia: a pilot study of moderate-altitude trekking effects on urodynamic indices. Am. J. Physiol. Physiol. https://doi.org/10.1152/ajprenal.00333.2019 (2019).

15. Wheatley, K., Creed, M. \& Mellor, A. Haematological changes at altitude. J. R. Army Med. Corps 157, 38-42 (2011). 
16. Hoon, R. S. et al. Effect of high-altitude exposure for 10 days on stroke volume and cardiac output. J. Appl. Physiol. 42, 722-727 (1977).

17. Naeije, R. Physiological adaptation of the cardiovascular system to high altitude. Prog. Cardiovasc. Dis. 52, 456-466 (2010).

18. Savla, J. J., Levine, B. D. \& Sadek, H. A. The effect of hypoxia on cardiovascular disease: friend or foe?. High Alt. Med. Biol. 19, 124-130 (2018).

19. Gilbert-Kawai, E. et al. Sublingual microcirculatory blood flow and vessel density in Sherpas at high altitude. J. Appl. Physiol. 122, 1011-1018 (2017).

20. Gilbert-Kawai, E. et al. Changes in labial capillary density on ascent to and descent from high altitude [version 1; referees: 2 approved]. F1000Research 5, (2016).

21. Hilty, M. P. et al. Recruitment of non-perfused sublingual capillaries increases microcirculatory oxygen extraction capacity throughout ascent to $7126 \mathrm{~m}$. J. Physiol. 597, 2623-2638 (2019).

22. Millet, G. P., Faiss, R. \& Pialoux, V. Point: hypobaric hypoxia induces/does not induce different responses from normobaric hypoxia. J. Appl. Physiol. 112, 1783-1784 (2012).

23. Millet, G. P. \& Debevec, T. CrossTalk proposal: barometric pressure, independent of, is the forgotten parameter in altitude physiology and mountain medicine. J. Physiol. 598, 893-896 (2020).

24. Zhang, B., Sun, Y., Xia, L. \& Gu, J. Time-dependent flow velocity measurement using two-dimensional color Doppler flow imaging and evaluation by Hagen-Poiseuille equation. Australas. Phys. Eng. Sci. Med. 38, 755-766 (2015).

25. Calbet, J. A. L. Chronic hypoxia increases blood pressure and noradrenaline spillover in healthy humans. J. Physiol. 551, 379-386 (2003).

26. Calbet, J. A. L. et al. Chronic hypoxia increases arterial blood pressure and reduces adenosine and ATP induced vasodilatation in skeletal muscle in healthy humans. Acta Physiol. 211, 574-584 (2014).

27. Barton, C., Ni, Z. \& Vaziri, N. D. Blood pressure response to hypoxia: role of nitric oxide synthase. Am. J. Hypertens. 16, 1043-1048 (2003).

28. Dopp, J. M., Reichmuth, K. J. \& Morgan, B. J. Obstructive sleep apnea and hypertension: mechanisms, evaluation, and management. Curr. Hypertens. Rep. 9, 529-534 (2007).

29. Casey, D. P. \& Joyner, M. J. Compensatory vasodilatation during hypoxic exercise: Mechanisms responsible for matching oxygen supply to demand. J. Physiol. 590, 6321-6326 (2012).

30. Kulandavelu, S., Balkan, W. \& Hare, J. M. Regulation of oxygen delivery to the body via hypoxic vasodilation. Proc. Natl. Acad. Sci. USA 112, 6254-6255 (2015)

31. Dinenno, F. A. Skeletal muscle vasodilation during systemic hypoxia in humans. J. Appl. Physiol. 120, 216-225 (2016).

32. Lamah, M., Mortimer, P. S. \& Dormandy, J. A. Study of temporal and perfusion physiology of skin capillaries in the dorsum of the foot. J. Vasc. Res. 38, 59-63 (2001).

33. do Amaral Tafner, P. F. et al. Recent advances in bedside microcirculation assessment in critically ill patients. Rev. Bras. Ter. intensive 29, 238-247 (2017).

34. Bourdillon, N., Mollard, P., Letournel, M., Beaudry, M. \& Richalet, J.-P. Non-invasive evaluation of the capillary recruitment in the human muscle during exercise in hypoxia. Respir. Physiol. Neurobiol. 165, 237-244 (2009).

35. Hanson, W. L. et al. Site of recruitment in the pulmonary microcirculation. J. Appl. Physiol. 66, 2079-2083 (1989).

36. Paparde, A., Nēringa-Martinsone, K., Plakane, L. \& Aivars, J. I. Nail fold capillary diameter changes in acute systemic hypoxia. Microvasc. Res. 93, 30-33 (2014).

37. Orbegozo -Cortés, D. et al. Normobaric hyperoxia alters the microcirculation in healthy volunteers. Microvasc. Res. 98, 23-8 (2015).

38. Kanoore Edul, V. S. et al. Quantitative assessment of the microcirculation in healthy volunteers and in patients with septic shock* Crit. Care Med. 40, 1443-1448 (2012).

39. Edul, V. S. K. et al. Dissociation between sublingual and gut microcirculation in the response to a fluid challenge in postoperative patients with abdominal sepsis. Ann. Intensive Care 4, 39 (2014).

40. Koh, I. H. J. et al. Microcirculatory evaluation in sepsis. Shock 34, 27-33 (2010).

41. Roberson, R. S. \& Bennett-Guerrero, E. Impact of red blood cell transfusion on global and regional measures of oxygenation. Mt. Sinai J. Med. 79, 66-74 (2012).

42. Roach, R. C. et al. The 2018 Lake Louise acute mountain sickness score. High Alt. Med. Biol. 19, 4-6 (2018).

43. Massey, M. J. et al. Microcirculatory perfusion disturbances in septic shock: results from the ProCESS trial. Crit. Care 22, 308 (2018).

44. Ince, C. et al. Second consensus on the assessment of sublingual microcirculation in critically ill patients: results from a task force of the European Society of Intensive Care Medicine. Intensive Care Med. 44, 281-299 (2018).

45. Massey, M. J. et al. The microcirculation image quality score: development and preliminary evaluation of a proposed approach to grading quality of image acquisition for bedside videomicroscopy. J. Crit. Care 28, 913-917 (2013).

46. Bernstein, D. P., Lemmens, H. J. M. \& Brodsky, J. B. Limitations of impedance cardiography. Obes. Surg. 15, 659-660 (2005).

47. Cotter, G., Schachner, A., Sasson, L., Dekel, H. \& Moshkovitz, Y. Impedance cardiography revisited. Physiol. Meas. 9, 817-827 (2006).

\section{Acknowledgments}

Figure 1 was created with BioRender.com. Dr. Limper reports a grant from the Faculty of Health, Witten/Herdecke University, Germany, during the conduct of the study (IFF 2020-26).

\section{Author contributions}

O.S., Y.H., J.M., M.K., J.Z., J.W., U.L., J.J., J.T. and C.J. conceived and designed the study. N.B., F.H., T.A., T.K., R.B., U.L. and C.J. conducted the experiments, O.S., U.L., M.L. and M.M. analyzed data. M.M., F.H., C.J., O.S., U.L., R.B., J.W. and J.T. wrote the manuscript. All authors read and approved the manuscript.

\section{Funding}

Open Access funding enabled and organized by Projekt DEAL.

\section{Competing interests}

The authors declare no competing interests.

\section{Additional information}

Supplementary information is available for this paper at https://doi.org/10.1038/s41598-020-77724-5.

Correspondence and requests for materials should be addressed to C.J. 
Reprints and permissions information is available at www.nature.com/reprints.

Publisher's note Springer Nature remains neutral with regard to jurisdictional claims in published maps and institutional affiliations.

(c) (i) Open Access This article is licensed under a Creative Commons Attribution 4.0 International License, which permits use, sharing, adaptation, distribution and reproduction in any medium or format, as long as you give appropriate credit to the original author(s) and the source, provide a link to the Creative Commons licence, and indicate if changes were made. The images or other third party material in this article are included in the article's Creative Commons licence, unless indicated otherwise in a credit line to the material. If material is not included in the article's Creative Commons licence and your intended use is not permitted by statutory regulation or exceeds the permitted use, you will need to obtain permission directly from the copyright holder. To view a copy of this licence, visit http://creativecommons.org/licenses/by/4.0/.

(C) The Author(s) 2020 